\title{
Numerical model of fracture formation in a coal seam
}

\author{
Maxim Makeev*, Sergei Sokolov, and Anastasiya Kolmakova \\ Federal Research Center for Coal and Coal Chemistry SB RAS, 650000, Kemerovo, Russia
}

\begin{abstract}
The article discusses the recovery process of fracture system formation after hydraulic fracturing in a coal seam, based on the conducted seismic studies using modern mathematical software packages. Model concepts of the fractures system development under hydrodynamic impact on a rock mass are considered, which make it possible to assess the nature of fractures propagation.
\end{abstract}

\section{Introduction}

The high gas content of coal seams requires increased attention when planning mining operations. This is primarily due to the mining safety rules. One of the main aspects of degasification is the natural gas recovery via boreholes drilled from intended mine workings before the start of coal mining [1,2]. The volume of the pore-fractured space has a significant effect on the degasification rate and the entirety of methane recovery. The method of hydraulic fracturing of a coal seam is widely used to influence the physical and mechanical properties of the extraction column. An informative method for assessing such impact is the seismic radioscopy made from mine workings.

To assess the effectiveness of hydraulic impact on a coal seam, performed to improve the safety of extraction column mining and to reduce its in-situ gas content, seismic studies were carried out at one of the coal mines of Kuzbass immediately before and after the hydraulic fracturing of the coal seam (HFCS) [3, 4].

\section{Methodologies}

The study was carried out in an excavation column section with a total length of $400 \mathrm{~m}$ based on the method of seismic radioscopy of a coal-rock massif on passing waves. The method of seismic radioscopy consists in registration of passing elastic waves in one of the parallel mine workings, while their generation is carried out in another. The receiving base is determined by the total number of seismic receivers groups, which are located at a given interval (for the given study $-20 \mathrm{~m}$ ). The position of seismic receivers is tied to real conditions based on the actual location of the underground infrastructure.

Initially, a seismic exploration was carried out in the area of the study section before hydraulic fracturing. At the time of measurement, the extraction column area was not disturbed by drilling hydraulic fracturing boreholes. Based on the results of seismic

\footnotetext{
*Corresponding author: m_makeev@uglemetan.ru
} 
measurements, the parameters of the signal propagating through the coal seam were analyzed, and a horizontal geophysical cross section was obtained (Fig. 1).

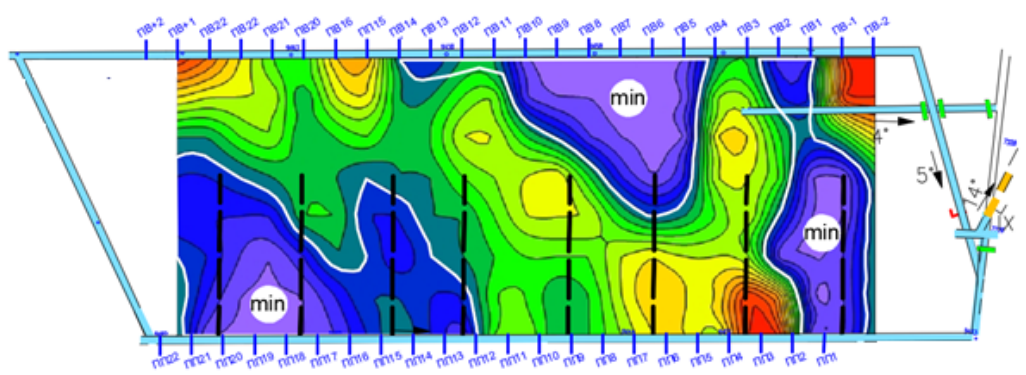

Scale of changes in velocity parameters of seismic signal transmission in the extraction column $\max$

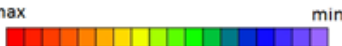

Zone of contrasting changes of coal seam physical and mechanical parameters in extraction column

hydraulic fracturing borehole

Fig. 1. Horizontal geophysical section of the velocity characteristics distribution before hydraulic fracturing.

According to the results of seismic measurements in a coal seam, a reduced velocity background with three contrasting zones of minimum velocities, characterized by the presence of coal in a weakened state and with the presence of mine workings, delineating the area of geophysical work is traced in the entire study area.

After the hydraulic impact implementation a repeated seismic exploration was carried out in the section area of the extraction column. Based on results of seismic measurements, parameters of the signal propagating through the coal seam were analyzed, and a horizontal geophysical cross section was obtained (Fig. 2).

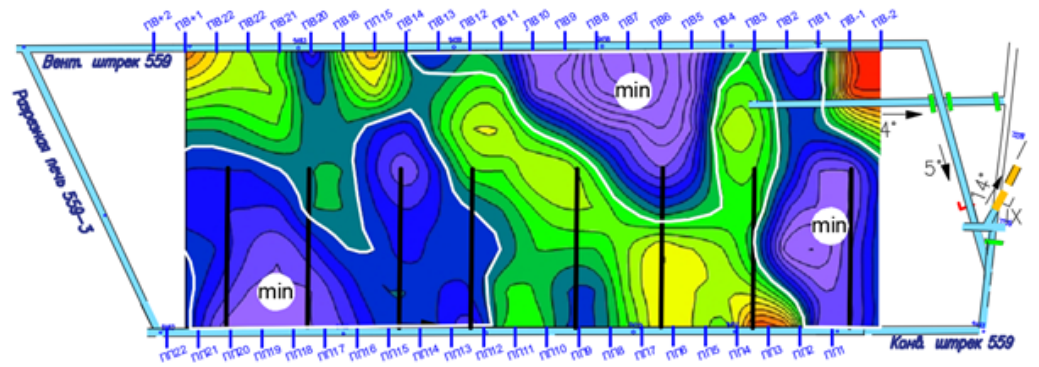

Scale of changes in velocity parameters of seismic signal transmission in the extraction column<smiles></smiles>

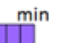

Zone of contrasting changes of coal seam physical and mechanical parameters in extraction column hydraulic fracturing borehole

Fig. 2. Horizontal geophysical section of velocity characteristics distribution after hydraulic fracturing.

According to the results of seismic radioscopy a general decrease in the background of seismic velocities within the study area and a contrasting increase in the area of minimum velocities zones are visually recorded, which is a sign of unloading due to hydraulic fracturing. Additionally, based on the application of software calculation procedures, a seismotomographic section was formed, reflecting the coal seam unloading degree, 
determined by the ratio of velocities difference recorded in measurements before and after hydraulic fracturing to the range of their possible change (Fig. 3).

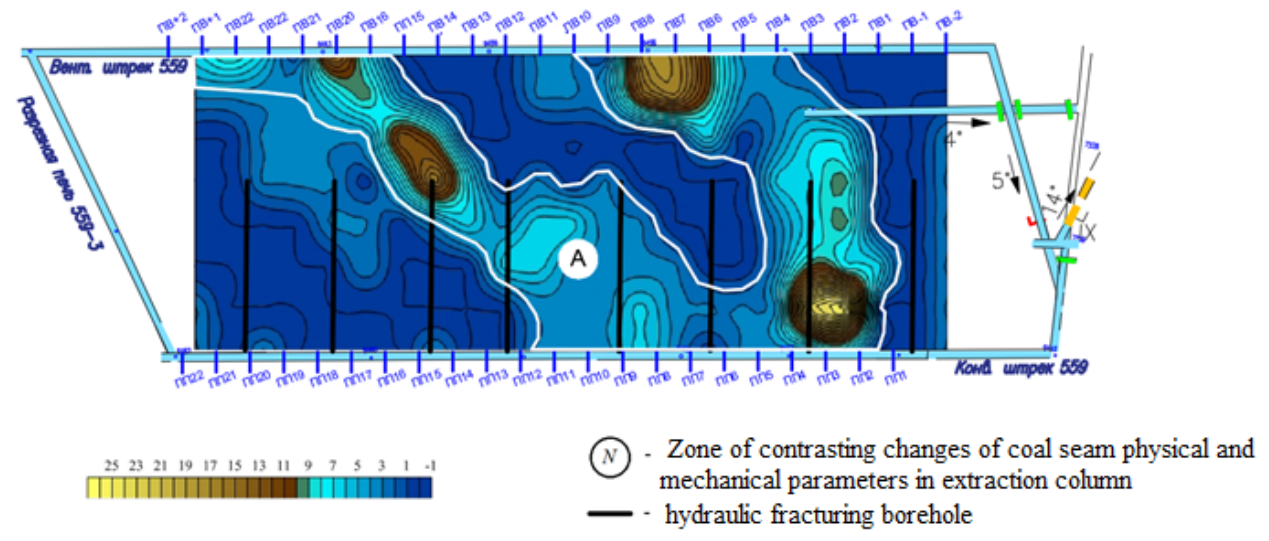

Fig. 3. Seismotomographic section, reflecting the coal seam unloading degree, recorded in measurements before and after hydraulic impact.

On the obtained seismotomographic section, the minimum (within 1\%) changes in the calculated ratio characterizing unloading are recorded throughout the entire study area. Within the coal seam reservoir, an extended zone with a change in the design ratio of 5$25 \%$ - A stands out in contrast. This zone is interpreted as an area of maximum unloading caused by a combination of natural and man-made causes, including the hydraulic fracturing.

The change in the general background of velocities after hydraulic fracturing is characterized by the fracture system formation along which the fluid propagates in different directions and under different pressures, depending on the physical and mechanical properties of rocks. It is possible to restore the process of fracture system formation, based on the conducted seismic studies, using modern mathematical software packages. The Subsurface Flow Module from the COMSOL Multiphysics software package was chosen to visualize the fracture system formation process, which includes equations resolve based on Darcy's law.

$$
\partial / \partial t(\rho \varepsilon)+\nabla \cdot(\rho u)=Q_{m}
$$

where, $\mathrm{u}=-\mathrm{k} / \mu(\nabla \mathrm{p}+\rho \mathrm{g} \nabla \mathrm{D}), \mathrm{p}$ - pressure $(\mathrm{Pa}) ; \mathrm{k}$-permeability $(\mathrm{mD}) ; \rho$-density of rock mass $\left(\mathrm{m}^{3} / \mathrm{kg}\right) ; \mu$ - fluid viscosity $(\mathrm{Pa} \cdot \mathrm{c}) ; \nabla \mathrm{D}-$ unit vector in the direction of gravity; $\mathrm{g}-$ acceleration of gravity $\left(\mathrm{m} / \mathrm{s}^{2}\right.$.).

Under the given boundary conditions for the hydraulic fracturing fluid flow through the rock mass perpendicular (normal) to the phase boundary:

$$
n \cdot \rho \cdot(k / \mu) \cdot(\nabla p+\rho g \nabla D)=\rho U_{0}
$$

where $U_{0}$ - initial value of speed according to Darcy's law $(\mathrm{m} / \mathrm{s},) \mathrm{n}$ - vector to the normal under given conditions.

To simulate the process of hydraulic fracturing using the software-analytical complex "Comsol 5.4", it is proposed to distinguish two main areas (A, B), within the boundaries bounded above and below by mine workings 200x200 m, with different physical and mechanical properties of rocks. These areas were identified based on the results of seismic radioscopy undertaken after hydraulic fracturing (Fig. 4). 
The physical and mechanical properties of coal during modeling were set through Young's elastic modulus (coal density and porosity). Porosity - from mining-geological conditions of coal deposits, and modulus of elasticity and density through the seismic waves propagation velocity. The known relationship between the elasticity modulus of coal and the seismic wave propagation velocity is known. So, for example, at a longitudinal wave propagation velocity of $0.95 \mathrm{~km} / \mathrm{s}$, Young's modulus of elasticity, E - $1600 \mathrm{MPa}$.

Presumably, the pressure area in the fracture system should not cross the boundaries of the selected areas (Figure 4, areas A-D).

Thus, for area A (Fig. 4), based on geophysical data, the initial values are set: permeability, $\mathrm{k}-3 \mathrm{mD}$, Young's modulus of elasticity, E - $1600 \mathrm{MPa}$, coal density $\rho_{A}-$ $1300 \mathrm{~kg} / \mathrm{m}^{3}$; porosity $\left(p_{A}\right)-20 \%$. For area B: permeability $\mathrm{k}-3 \mathrm{mD}$, Young's modulus of elasticity, E $-1300 \mathrm{MPa}$, density of coal $\left(\rho_{B}\right)-1400 \mathrm{~kg} / \mathrm{m}^{3}$; porosity $\left(p_{B}\right)-18 \%$.

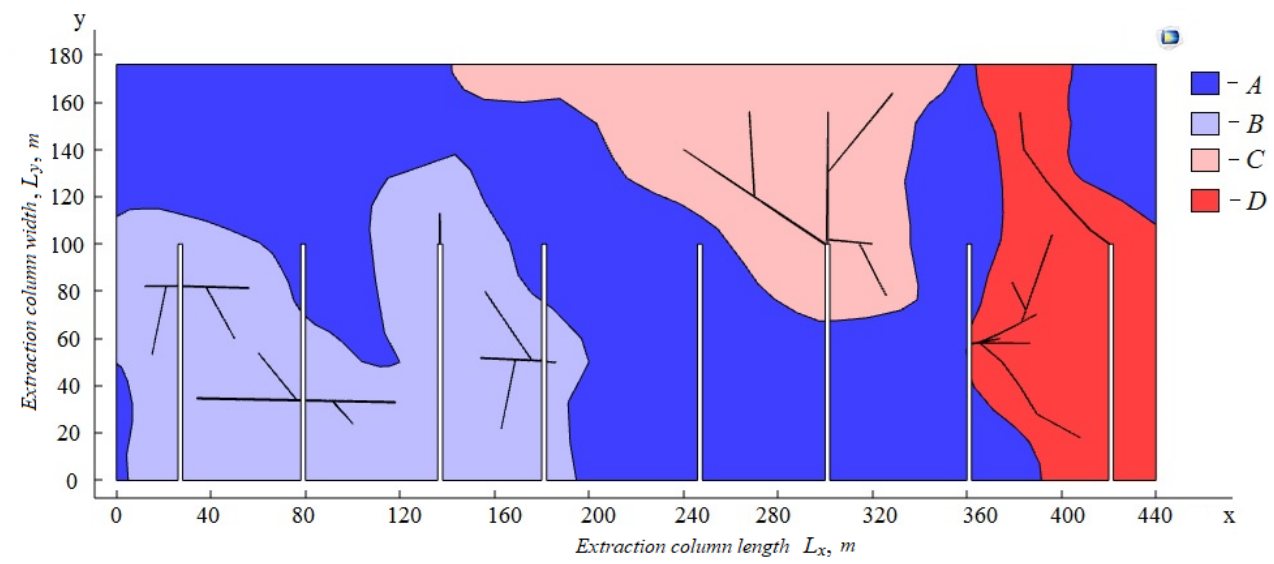

Fig. 4. Boundaries of study areas A, B, C and D, including hydraulic fracture boreholes and fracture system model.

After plotting the study areas and setting the initial conditions for the calculation, a developed system of fractures was modeled, which describes the geophysical section of velocity characteristics distribution in the extraction column area.

To simulate the process of fracture formation in a rock mass under the influence of fluid supply under pressure, it has been suggested that fluid enters the rock mass at high pressure through a borehole interval sealed with a packer in accordance with the hydraulic fracturing technique.

Then, the model sets the gradual development of fractures throughout the rock mass. To describe the fractures propagation in a rock mass, a new system of fractures was alternately set in the model (Fig. 5). The graphical construction of fractures was plotted in an interactive mode. Further, at the "fracture-rock mass" interface, using the built-in "Fracture flow" function, the initial conditions were set in accordance with equation (2), corresponding to fluid assage through fractured rocks.

\section{Results and discussion}

The results of modeling the distribution of fluid pressure in a rock mass with a developed fracture system during hydraulic fracturing are shown in Fig. 5.

Model concepts of the fracture system development under hydrodynamic impact a rock mass made it possible to assess the nature of their propagation. The results of mathematical modeling analysis showed the comparability of the full-scale experiment with the model. In 
the future, it is planned to adapt the model to quantify the methane amount released from fractures into the borehole.

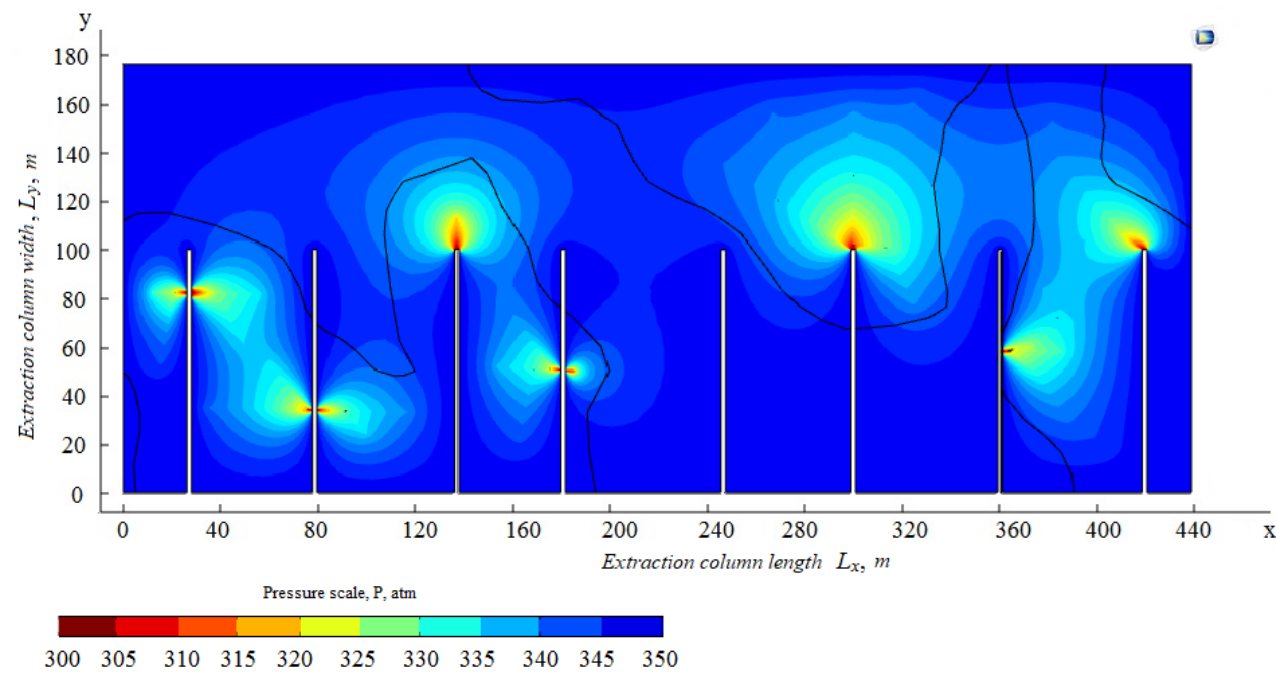

Fig. 5. Distribution of fluid pressure in the rock mass when feeding into the borehole and fracture system formation

\section{Conclusion}

To assess the effectiveness of measures to unload the coal seam in the studied area of the extraction column, geophysical studies were carried out, which enabled to establish a decrease in velocities general background after hydraulic fracturing and a noticeable increase in the area of a reduced velocities zone "min". geomechanical state of the coal seam. The performed studies indicate the possibility of using the seismic radioscopy method to determine the effect of hydraulic fracturing on the geomechanical state of the coal seam.

The results obtained can be used to clarify mining and geological conditions and develop measures aimed at improving the efficiency of coal mining and the safety of mining operations.

The conducted research was funded by the Russian Science Foundation (project No 17-17-01143).

\section{References}

1. V.I. Klishin, G.Yu. Opruk, A.V. Sentyurev, A.V. Nikolaev, Ugol, 11, 12-16 (2015)

2. A.I. Khasanova, E.M. Almukhametova, N.Kh. Gabdrakhmanov, Problems of collection, preparation and transportation of oil and oil products, 1, 7-13 (2016)

3. O.V. Tailakov, S.V. Sokolov, A.V. Gerasimov, A.A. Kolmakova, Gorny information and analytical bulletin, S49, 275-282 (2018)

4. O.V. Tailakov, S.V. Sokolov, E.A. Saltymakov, Science-intensive technologies for the development and use of mineral resources, 4, 437-441 (2018) 